of this collection of Nigerian sculpture makes one realize the complete inadequacy of present methods of classifying negro African sculpture. What, for instance, is meant by "Tribal sculpture', or by 'Ibo, Ibibio and Ekoi styles'? The Ugbom statuettes (nos. 22 I-s) are labelled Ibo presumably because their former owners spoke this language, but they have nothing in common with other Ibo sculpture and little with Ibibio. They were fashioned a few generations ago by local carvers for a new 'Play'-a women's fertility danceproduced by a few Ibo villages on the Ibo-Ibibio border. The style of these carvings is unique but, like the play, it is now dead and the only good examples of it are buried in a few Nigerian museums. On the other hand, the seated mother and child statuettes (nos. 3 I I and 3 I2) now classified as 'Afo tribe' and previously labelled ' Tiv' are quite as obviously a derivative of the Yoruba style as the Igala and Idoma masks (nos. 288-92) are derivatives of the northern Ibo style, while the masks included under 'Ekoi tribe' could have been made by any of the peoples on or near the Cross River. It is easy enough to pick holes in systems of classification devised by museum curators and art connoisseurs, but until anthropologists are prepared to devote as much study to African material culture and African aesthetics as they do to African social structure we shall have to put up with it, and with such notes as 'Tiv-nos. 295-300. Six human figures probably connected with the ancestor cult.'

A far more important point, and one that has received no notice in the catalogue or elsewhere, concerns the number of masterpieces in this exhibition which were discovered and collected recently. In the case of the better-known negro sculpture of the French colonies no significant additions have been made since Carl Kjersmeier popularized Bambara sculpture in 1935 and most of the best examples are in the hands of private collectors. In the case of Nigerian sculpture the position is the reverse. A great deal of the more significant sculpture was collected in the thirties and some of the more exciting styles were unknown, except to a few people in Nigeria, until after the last war. This exhibition is a belated tribute to the years of selfless work begun by Government Education officers in the nineteenthirties and continued by the Antiquities Department after the war, and in particular to that of Mr. K. C. Murray who, first as an Arts and Crafts officer and later as Curator of the Lagos Museum, has devoted the best part of his life to the recording, collecting, and preservation of Nigerian art.

[Communicated by Mr. G. I. Jones]

\title{
The Eastern Africa Law Reports
}

A NEw series of Law Reports for East Africa is being issued by Messrs. Butterworth and includes reports of decisions of the superior courts in Kenya, Uganda, Tanganyika, Zanzibar, Aden, Seychelles, and Somaliland; of the Court of Appeal for Eastern Africa; and of the Privy Council on Appeal from these courts. The reports are issued in quarterly parts beginning with the year 1957. The 1957 and 1958 Reports are available in bound volume form and three of the four parts for 1 959 have already been issued. Further details may be obtained from Messrs. Butterworth \& Co. (Publishers) Ltd., 88 Kingsway, London, W.C. 2.

\section{Africana in Tenri, Japan}

A catalogue has been published of books relating to Africa in the Tenri Central Library, Japan. The collection comprises some 3,200 titles of books and periodicals, most of which came from the library of the late Viscount Takesada Tokugawa, sometime Professor of Tokyo University and Director of the Naval Institute for Technology. The majority of the titles date from the first half of the present century down to 1940 and are mostly works of travel, hunting, and zoology, a few modern anthropological studies being included, however. Some 70 titles date from the eighteenth century and earlier. 